\title{
Auditory Health and Risk Factors in Rural Workers Exposed to Pesticides in Piedade de Caratinga County-Minas Gerais
}

\author{
Paula Critina da Silva Botelho1, Valdênia Gomes Rocha², Tamires Ribeiro Dutra², \\ Júlio César Alves Feitosa ${ }^{3}$, Ricardo Campos de Assis ${ }^{2}$, Thiago Sande Miguel, \\ Nayrton Kalys Cruz dos Anjos ${ }^{4}$, Daniel Almeida da Costa ${ }^{5}$, Lina Claudia Pereira Lopes ${ }^{6}$, \\ Lamara Laguardia Valente Rocha ${ }^{7}$
}

\author{
${ }^{1}$ Department of Nursing, University Center of Caratinga, Caratinga, Brazil \\ ${ }^{2}$ Graduating in medicine, University Center of Caratinga, Caratinga, Brazil \\ ${ }^{3}$ Graduating in Psychology, University Center of Caratinga, Caratinga, Brazil \\ ${ }^{4}$ The Medical School at the Center of Higher Education of Valença, Valença, Brazil \\ ${ }^{5}$ Department of Medicine, Graduate Program in Medicine, Faculty of Medicine of Valencia, Brazil \\ ${ }^{6}$ Speech Therapist, The Medical School at the Center of Higher Education of Valença, Valença, Brazil \\ ${ }^{7}$ Department of Morphology, University Center of Caratinga, Caratinga, Brazil \\ Email: professordanielfmv@gmail.com
}

How to cite this paper: Botelho, P.C.S., Rocha, V.G., Dutra, T.R., Feitosa, J.C.A., de Assis, R.C., Miguel, T.S., dos Anjos, N.K.C., da Costa, D.A., Lopes, L.C.P. and Rocha, L.L.V. (2017) Auditory Health and Risk Factors in Rural Workers Exposed to Pesticides in Piedade de Caratinga CountyMinas Gerais. Journal of Biosciences and Medicines, 5, 37-55.

https://doi.org/10.4236/jbm.2017.57005

Received: May 4, 2017

Accepted: July 17, 2017

Published: July 20, 2017

Copyright (c) 2017 by authors and Scientific Research Publishing Inc. This work is licensed under the Creative Commons Attribution International License (CC BY 4.0).

http://creativecommons.org/licenses/by/4.0/

c. (i) Open Access

\begin{abstract}
In Brazil, the amount of pesticides consumed doubled in the last 10 years. Thus, in 2008 it assumed the lead position in the world. However, its indiscriminate application in agriculture without the use of the necessary care has contributed to environmental degradation and increased occupational exposures, making it a serious health problem in the country. The recent study looked to evaluate the auditory health and risk factors in rural workers exposed to pesticides in Piedade de Caratinga County-MG, and chart their socioeconomic profile and lifestyle while identifying the types of crops and the use and management of pesticides. Developed, then, a descriptive and exploratory study involving 23 men, rural workers, exposed to pesticides, with no history of exposure to noise, with changes in meatoscopy and aged $\leq 50$ years of age. The results show the sample consisted of 23 men with a mean age of $36.7 \pm 9.3$, whom have low education, with a monthly income of 1 minimum wage, working in the fields for over 15 years. There was a predominance of horticulture using organophosphate pesticides and pyrethroids. Part of the sample shows auditory loss, the most common sensorineural conductive loss. It is essential that the population exposed to this type of risk is informed and receives guidance from educational campaigns developed by the multidisciplinary team of basic health units.
\end{abstract}




\section{Keywords}

Auditory Health, Pesticides, Audiometry and Rural Workers

\section{Introduction}

In Brazil, the amount of pesticides consumed doubled in the last 10 years, thus, in 2008 Brazil assumed the lead position in the world. In 2011, the country used over 852.8 million liters of pesticide [1]. Its indiscriminate application in agriculture without the use of the necessary care has contributed to environmental degradation and increased occupational exposures making it a serious health problem in the country.

According to the data of the National System of Toxic-Pharmacological Information (SINITOX) in 2010, there were 10,269 cases of pesticide poisoning in general, of which, 1,347 were caused by occupational circumstances. It is observed that there is a large underreporting of adverse effects, especially longterm, which can determine chronic diseases [2].

The types of pesticides that cause variable degree of toxicity and ototoxicity to humans are organophosphates and pyrethroids [3]. Chronic exposures to these pesticides affect the auditory system at the central and peripheral levels, regardless of exposures concomitant to noise [4].

Ototoxicity can be defined as the result of the action of certain chemicals that injure the anterior/posterior maze, leading to auditory loss with or without vertigo, nausea and gait instability, and should be studied and considered as a public health problem [5].

The auditory loss caused by pesticides may occur insidiously or not and its severity will depend on factors such as the amount, the time of exposure and the interaction with the ototoxic agent. Usually this loss occurs symmetrically bilateral. The symptoms resulting in vestibular alterations are dizziness and vertigo, which may appear early and more intensely than the auditory [6].

In Brazil there are few studies that report the association between exposure to pesticides and auditory alterations, but all authors concord with the relationship [7] [8] [9] [10].

Studies made a comparison between exposure to pesticides and noise with hearing loss, and most came to the conclusion that there is evidence that chemicals can lead to hearing loss regardless of the presence of noise [7] [8] [9] [10].

Minas Gerais is one of the largest producers of coffee in Brazil [11]. Research conducted involving farmers in the state showed that most use organophosphates and pyrethoids [12].

In the region of Caratinga, located in east Minas Gerais, studies indicate the use of more than 39 types of pesticides in tomato culture (Solanumlycopersicum), being mostly the chemical class of organophosphates and pyrethroids [13] $[14]$. 
Piedade de Caratinga County, located in east Minas Gerais relies on agriculture as one of the main economic activities, coffee being the most anticipated, and in the dry season the coffee producers become olericulture [15].

Because this region is predominantly agricultural with extensive use of pesticides, especially organophosphates and pyrethroids, both in cultivation of coffee and tomato, this study sought to evaluate the auditory health and risk factors in rural workers exposed to pesticides in Piedade de Caratinga County, MG, and chart their socioeconomic profile and lifestyle, while identifying the types of crops and the use and management of pesticides.

\section{Materials and Methods}

First, This is a descriptive and exploratory research with quantitative and qualitative approach to the "basic purpose to develop, clarify and modify concepts and ideas for the design of further approaches" [16].

The study was conducted from January to June 2013, in the rural area of the municipality of Piedade de Caratingalocated in east Minas Gerais, in the middle region Vale do Rio Doce, belonging to the micro-region of Caratinga-Minas Gerais.

It has a land area of $42,5127.96 \mathrm{mi} 2$, population of 7,110 inhabitants, altitude 874.89 yds., average temperature of $68^{\circ} \mathrm{F}$ in winter and $84.2^{\circ} \mathrm{F}$ in the summer. The topography is smooth and the street layout is in bottom of the valley. Coffee production is the main economic activity due to the altitude and mild climate. During the dry season of these products, the producers become olericultures, that follow to the municipalities in the region and Belo Horizonte [11].

Rural workers, whose main activity is spraying pesticides in cultures and who attended the audiometric examination beyond the delivery of the questionnaire and explained signed informed consents, were selected. Exclusion criteria have the use of heavy machines that emit noises, changes in meatoscopy and age above 50 years.

Thus, the final sample was selected as a matter of convenience and had 23 men, rural workers, who fulfilled the principle of inclusion and exclusion established. The absence of women in the study sample was not criterion of intentional exclusion of the authors of this research. But an absence of this kind was justified by the fact that, when determining the sample was intended to initially work with the number of rural workers who were representative for the population of these rural areas under study. However, when making contact with the owners of larger farms, they did not allow the development of the project. We then decided to work with small farmers who were self-employed, and whose women did not participate in the work with the crop, and were responsible for animal care and the home.

The audiometric tests were performed in acoustic cabins, using clinical audiometer BETA 6000 - Beta Medical, calibrated according to standard methods. The professional responsible for them was a properly qualified speech therapist and registered in its class organ. In testing the therapist had no prior knowledge 
of the type of previous exposure of each individual. The audiogram of each rural worker was issued under ASHA [17].

A semi-structured interview was conducted using questionnaires adapted from the study of Kos [18], in which data were obtained on socioeconomic and lifestyle profile, types of crops, use and management of pesticidesauditory signs and clinical symptoms. The following information was considered: age, gender, education level, monthly income, smoking and alcohol consumption.

In relation to the types of crops, the data of the use and management of pesticides was collected about working hours, daily working periods, type of cultivation, types of chemicals for agricultural use utilized, equipment used to apply the product, contact with pesticides, knowledge of the risks of pesticides to human health, guidance on the risks at work, type of information about these risks, training on first aid, packaging disposal and use of personal protective equipment (PPE), who conducted the training, use of PPE to handle the products, which PPE were used, if after the use of pesticides any specific hygiene routine was implemented and what they were.

To understand the possible effects of the chronic use of pesticides on the health of rural workers, a questionnaire that consisted of questions concerning: incidence of poisoning by pesticides, tinnitus, dizziness presented during or after contact with pesticides and the presence of otorrhea and earache was used.

The otoscopy was performed in all rural workers to check the integrity of the pinna and ears as to the existence of injury such as obstruction of the external auditory meatus, perforated eardrum and hearing of non-occupational origin. Those who submit any such changes would be excluded from research.

Data was analyzed employing descriptive and inferential statistics. Statistical analysis was performed using SPSS software, version 11.0. Quantitative variables were described by mean and standard deviation. The results were presented in tables. To determine the association between the qualitative variables in the study, we used the chi-square test. The significance level was $5 \%$, where significant values of $\mathrm{p} \leq 0.05$ were considered.

All received information related to the research and later signed the Consent and Informed Agreement (Annex I) according to Resolution No. 196 of October 10, 1996 of the National Health Council (CNS), involving research on human subjects. The project was submitted to the Ethics Committee of Caratinga University Center where he received permission for the study was conducted.

\section{Results}

In order to trace the socioeconomic profile and lifestyle sample in the study, the parameters whose results are in Table 1, were considered.

Define According to the data reported in Table 2, the study population was composed of individuals with a mean age of $36.7 \pm 9.3$ years, only for males.

Regarding education, $69.6 \%$ attended elementary school from 1 st to 5 th grade; $21.7 \%$ reported having attended 6th to 9 th grade and $8.7 \%$ attended high school. 
P. C. S. Botelho et al.

Table 1. Socio-economic profile and lifestyle of 23 rural workers exposed to pesticides from Piedade de Caratinga-MG.

\begin{tabular}{|c|c|c|}
\hline Variables & $\mathrm{n}$ & $\%$ \\
\hline \multicolumn{3}{|l|}{ Age (years) } \\
\hline Mean \pm standard deviation & \multicolumn{2}{|c|}{$36.7 \pm 9.3$} \\
\hline Minimum & \multicolumn{2}{|c|}{18} \\
\hline Maximum & \multicolumn{2}{|c|}{48} \\
\hline \multicolumn{3}{|l|}{ Education } \\
\hline $1^{\text {st }}$ grade to $5^{\text {th }}$ grade & 16 & 69.6 \\
\hline $6^{\text {th }}$ grade to $9^{\text {th }}$ grade & 5 & 21.7 \\
\hline High School & 2 & 8.7 \\
\hline \multicolumn{3}{|l|}{ Monthly Income (Salary) } \\
\hline$<1$ & 5 & 21.7 \\
\hline 1 & 14 & 60.9 \\
\hline 2 a 3 & 4 & 17.4 \\
\hline \multicolumn{3}{|l|}{ Time worked (years) } \\
\hline$<3$ & 2 & 8.7 \\
\hline 3 a 5 & 3 & 13.0 \\
\hline 5.1 a 10 & 2 & 8.7 \\
\hline 10.1 de 15 & 6 & 26.1 \\
\hline$>15$ & 10 & 43.5 \\
\hline \multicolumn{3}{|l|}{ Smoker } \\
\hline Yes & 7 & 30.4 \\
\hline No & 16 & 69.6 \\
\hline \multicolumn{3}{|l|}{ Drinker } \\
\hline Yes & 12 & 52.8 \\
\hline No & 11 & 47.8 \\
\hline \multicolumn{3}{|l|}{ Working period (hours) } \\
\hline 6 & 2 & 8.7 \\
\hline 8 & 13 & 56.5 \\
\hline 10 & 4 & 17.4 \\
\hline 12 & 2 & 8.7 \\
\hline Other & 2 & 8.7 \\
\hline
\end{tabular}


Table 2. Use and management of pesticides and knowledge of personal protective equipment according to 23 rural workers exposed from Piedade de Caratinga-MG.

\begin{tabular}{|c|c|c|c|}
\hline Variables & $\mathbf{n}$ & $\%$ & \\
\hline \multicolumn{4}{|l|}{ Type of crop } \\
\hline Tomato & 10 & 43.5 & \\
\hline Coffee & 7 & 30.4 & \\
\hline Tomato and Coffee & 3 & 13 & \\
\hline Outros & 11 & 47.8 & \\
\hline Type of chemical product agriculturally used & $\mathbf{n}$ & Class & $\%$ \\
\hline Meothrin ${ }^{\circledast}$ & 13 & I & 56.5 \\
\hline Tamaron $^{\oplus}$ & 12 & I & 52.2 \\
\hline Manzate $^{\oplus}$ & 16 & I & 69.6 \\
\hline Vertimec $^{\oplus}$ & 15 & III & 65.2 \\
\hline Actara $^{\infty}$ & 12 & III & 52.2 \\
\hline Roundup ${ }^{\oplus}$ & 21 & III & 91.3 \\
\hline Endosulfan $^{\infty}$ & 2 & I & 8.7 \\
\hline Opera $^{\oplus}$ & 8 & II & 34.8 \\
\hline Baysiston $^{\oplus}$ & 0 & III & 0 \\
\hline Impact $^{\oplus}$ & 1 & I & 4,3 \\
\hline Supera ${ }^{\infty}$ & 2 & II & 8.7 \\
\hline Supera $^{\infty}$ & 9 & III & 39.1 \\
\hline Supera ${ }^{\infty}$ & 9 & & 39.1 \\
\hline Lead equipment for application & $\mathbf{n}$ & $\%$ & \\
\hline Bar and hose sprayer & 3 & 13 & \\
\hline Manual knapsack sprayer & 16 & 69.6 & \\
\hline Mechanized knapsack sprayer & 3 & 13 & \\
\hline Stationary sprayer with motor & 6 & 26.1 & \\
\hline Other & 1 & 4.3 & \\
\hline Contact with pesticides & $\mathbf{n}$ & $\%$ & \\
\hline Applying the product & 18 & 78.3 & \\
\hline Preparing the solution & 17 & 73.9 & \\
\hline Cleaning the equipment and utensils & 12 & 52.2 & \\
\hline In transport and storage & 12 & 52.2 & \\
\hline Entrance in the tillage with recent applications & 7 & 30.4 & \\
\hline Other & 0 & 0 & \\
\hline
\end{tabular}




\section{Continued}

\section{Use of Personal Protection Equipment (PPE)}

Yes

Received orientation about the risks of their work

Yes

No

Who has guided you about the risks of your work?

Neighbors

Other

Received training about first aid and disposal of PPE

Yes

Use of PPE when handling the product

Yes

No

Sometimes

If yes, which ones?

Gloves

Hat

Impermeable clothing

Chemical mask

Others

Use of product is proceeded by a hygiene routine

Yes

No

Specific hygience routine

Wash hands and face each time after dealing with these products.

Take a complete shower after work with these products. 
When asked about the monthly income, $60.9 \%$ said they receive a minimum wage per month; $21.7 \%$ receive less than the minimum wage; $17.4 \%$ receive between two and three monthly salaries.

Considering aspects relative to the use and management of pesticides and in view of the working time in coffee and tomato plantations, $8.7 \%$ reported that they worked less than three years; $13.0 \%$ from 3.1 to 5 years; $8.7 \% 5.1$ to 10 years; $26.1 \%$ from 10.1 to 15 years; $43.5 \%$ more than fifteen years (Table 1 ).

When asked about smoking habits, 30.4\% said they smoke; $69.6 \%$ reported that they did not. In regards to consumption of alcohol, $52.8 \%$ said they consume alcohol; $47.8 \%$ do not consume alcohol. Regarding the daily working period, $8.7 \%$ work six hours a day; $56.5 \%$ eight hours; $17.4 \%$ ten o'clock; $8.7 \%$ twelve hours and other remaining $8.7 \%$ could not inform about the time spent at work (Table 1).

An important factor for the increased risk of exposure to pesticides refers to the use and handling of these products, Table 2 reported the findings relating to the variables that characterize this practice.

As recorded in Table 2 and considering the type of existing agriculture in rural Piedade de Caratinga, it was found that $43.5 \%$ of the crops are tomatoes; $30.4 \%$ coffee; $13 \%$ culture both (tomato and coffee) and $47.8 \%$ other types of crops ranging from vegetables and fruits.

Technical analysis about the type of agricultural defense used in coffee, tomato and other crop cultivation, there are a series of pesticides used, listed as follows: Roundup ${ }^{\varpi}(91.3 \%)$ whose toxicological classification is III, Manzate ${ }^{\varpi}(69.6 \%)$ toxicological class I, Vertimec ${ }^{\circledast}(65.2 \%)$ belonging to class III, Meothrin ${ }^{\circledast}(56.5 \%)$ followed by Tamaron ${ }^{\otimes}(52.2 \%)$ with extremely toxic type I toxicology (Table 2).

For the application of these pesticides it is necessary to use their own equipment, these workers were asked about what equipment they used. The results of the answers are shown in Table 2 , where it is possible to verify that $13 \%$ use the bar and hose sprayer for application in the crops; $69.6 \%$ manual knapsack sprayer; $13 \%$ use the mechanized knapsack sprayer; $26.1 \%$ use the stationary spray with motor and another $4.3 \%$ use of another form of application.

Regarding the handling of pesticides, the question was asked about how contact with the product would be. $78.3 \%$ said that the only contact had with the pesticide would be when it is applied; $73.9 \%$ in the preparation of the solution; $52.2 \%$ during the cleaning of the equipment and utensils; $52.2 \%$ during transportation and storage; and $30.4 \%$ said that contact with pesticide is had when entering a crop soon after application (Table 2).

According to Table 2 in regards to the use of some kind of personal protective equipment (PPE) 39.1\% said they use; $39.1 \%$ said they did not use and $21.7 \%$ reported that they sometimes use it. When asked if they received any guidance on the risks that this type of work with pesticides could cause, $65.2 \%$ answered that yes, they received information about the risk inherent to this type of work and $34.8 \%$ reported that they received no guidance about the real risks of handling pesticides. 
Still about this same matter, workers were asked who passed these guidelines to them, $80 \%$ said that friends, family and other people guided them and $20 \%$ that neighbors were responsible for keeping them informed. Regarding first-aid training, disposal of pesticide containers and PPE, 21.7\% said they received training and $78.3 \%$ did not (Table 2).

Regarding the use of PPE for the application of the product in crops, $43.5 \%$ said that they use protection adequately, $34.8 \%$ do not use PPE and $21.7 \%$ that they sometimes use it. Still related to this topic, they were asked about which PPE they used to avoid direct contact with pesticides, $69.6 \%$ said they use boots for prevention; $43.5 \%$ gloves; $39.1 \%$ hats; $26.1 \%$ impermeable clothing; $56.5 \%$ chemical masks and $8.7 \%$ reported using other forms of protection (Table 2).

Considering the data in Table 2, in relation to the hygiene procedures soon after application of pesticides, $82.6 \%$ said that they performed a hygiene routine and $17.4 \%$ did not. When asked about what specific hygiene habits they adopted; 87\% answered that they wash their hands and face every time they deal with a pesticide; $91.3 \%$ who take a complete bath after working with pesticides; $69.6 \%$ change clothes right after using these products and $65.2 \%$ said they avoid eating or smoking during the application of these products.

The routine use of these harmful pesticides is harmful to health, it was asked if some of these workers showed some type of intoxication, $30.4 \%$ said they already showed signs of intoxication and $69.6 \%$ have never had such signs.

The last question of this questionnaire, was about if soon after the application of pesticides, there was some sign or symptom relative to the use of these products; $21.7 \%$ said they felt dizzy; $26.1 \%$ had difficulty hearing; $21.7 \%$ lack balance; $30.4 \%$ nausea; $34.8 \%$ felt congestion in ear; $13 \%$ vomiting; $34.8 \%$ ringing in the ears; $8.7 \%$ tearing and ear pain; $21.7 \%$ no symptoms and $43.5 \%$ presented other types of signs and symptoms.

The interviewees were also asked about the impression they had about their auditory health, in regards to right ear hearing, $87 \%$ reported it being good; $8.7 \%$ that is regular and another $4.3 \%$ that is bad. In regards to left ear hearing, 100\% of respondents stated that it was good.. In addition to the noises inherent in their activity in the coffee and tomato plantations, it was sought to know if they are exposed to other types of noise outside work noise and 100\% said they are not exposed.

In order to have a better view on the auditory health of these workers, meatoscopy and audiometry exams were performed, the results of which are presented in Table 3.

According to Table 3, it can be observed that no rural worker presented lesion of the auricular pavilion, thus presenting normal diagnosis for meatoscopy. In relation to the audiometry, auditory loss was found in $34.78 \%$ of the patients evaluated, of whom $21.74 \%$ had a conductive type lesion and $13.04 \%$ had sensorineural auditory loss. As for the affected ear, it was found that in $21.74 \%$ of the sample both ears were affected, $8.69 \%$ presented auditory loss only in the right ear and $4.35 \%$ in the left ear. Considering the audiological opinion, it was 
Table 3. Meatoscopy and audiometry profile of the 23 rural workers exposed to pesticides in the Caratinga Pìedade County-MG.

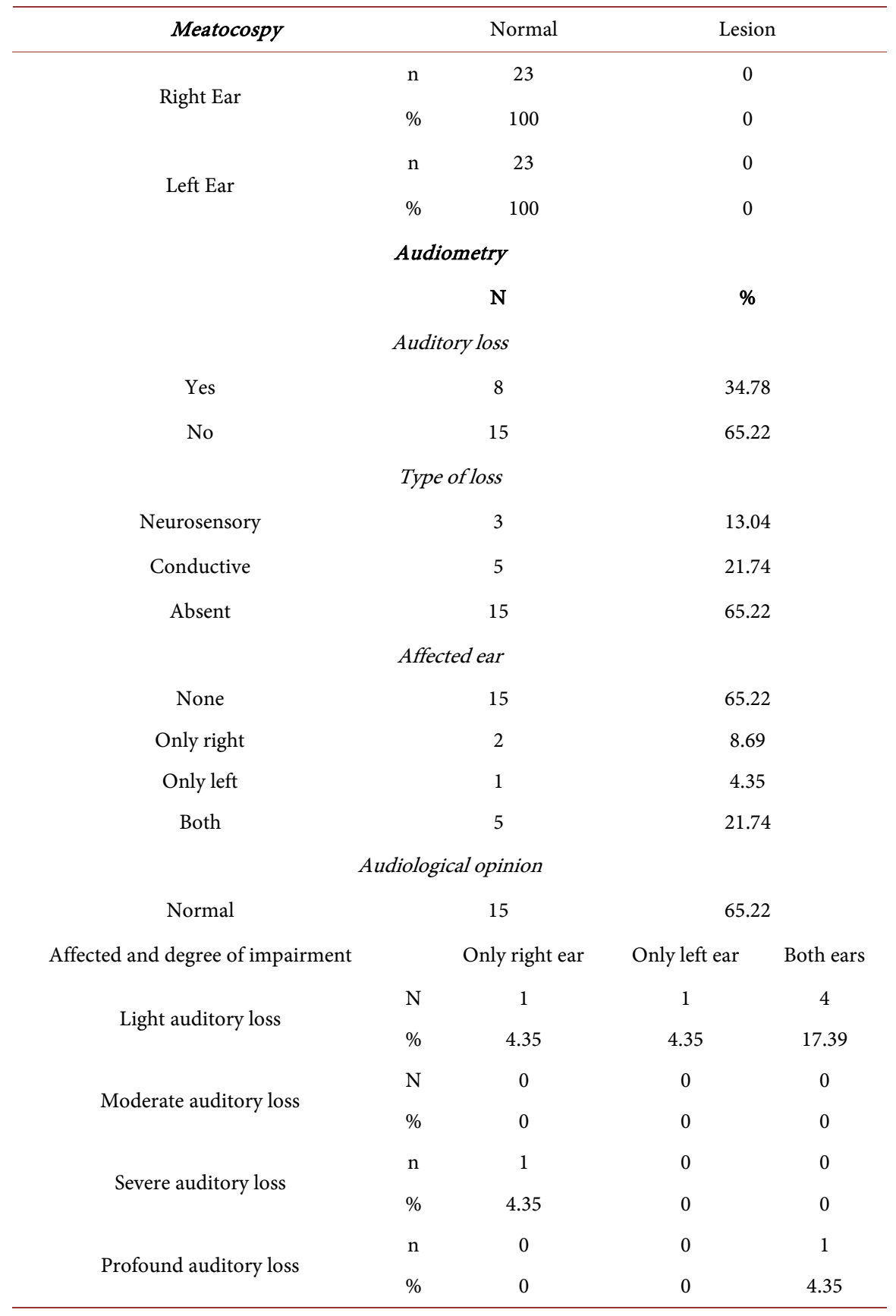

observed that in $65.22 \%$ normal results were obtained, in those who presented some lesion, $17.39 \%$ were diagnosed with mild auditory loss in both ears, only in the right ear $(4.35 \%)$ or only in the left $(4.35 \%)$. Other degrees of impairment were also diagnosed as severe auditory loss in the right ear $(4.35 \%)$ and profound auditory loss in both ears (4.35\%). Considering the data obtained in the audiometry referring to the frequency in $\mathrm{HZ}$ and the possible involvement among those rural workers exposed to the pesticide, the results shown in Figure 1 were obtained. 


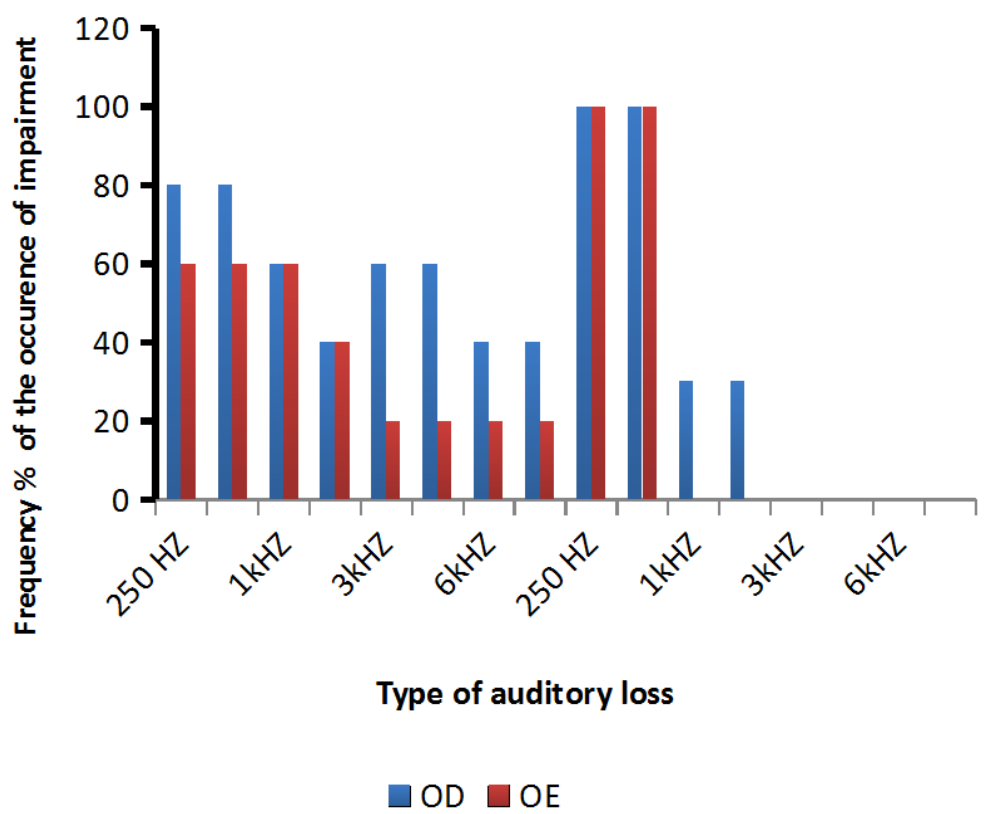

Figure 1. Occurrence of impairment according to the frequencies in HZ, among the eight rural workers who presented auditory loss, separated according to the type of loss.

According to the data recorded in Figure 1, considering the initial observation in the loss of the conductive type, it is observed that for the right and left ears, low sound frequencies (from $250 \mathrm{HZ}$ to $1 \mathrm{kHZ}$ ) percentages were greater than when compared to what was seen in the higher sound frequencies $(2 \mathrm{kHZ}$ to $8 \mathrm{kHZ}$ ). Considering also the conductive loss and the impairment of the frequencies, it is observed that the right ear presents greater percentages for alterations in the higher frequencies than the left ear.

Analyzing the results of the workers with neurosensory loss, the impairment of lower frequencies for both right and left ear was not recorded; however, 100\% of them had a higher frequency, ranging from $4 \mathrm{kHz}$ to $8 \mathrm{KHz}$ for the right ear and, from $3 \mathrm{kHz}$ to $6 \mathrm{kHz}$ for the left ear.

The possible associations between several factors such as socioeconomics, the use of PPE, the working period, the auditory loss and the signs and symptoms reported by the workers are recorded in Table 4.

Considering the socioeconomic factors, only significant associations between age and the symptom of intoxication were observed, with higher percentages $(52.17 \%)$ in individuals aged over 30 years when compared to those under 30 years of age $(0.00 \%)$. Another association established through statistical analysis was between the use of PPE and the occurrence of ringing in ears and dizziness, with a higher percentage (47.86\%) for the absence of these symptoms among workers who claimed to use the equipment. The presence of ringing in the ears and dizziness was reported with percentages (17.39\%) in the group of those who stated that they did not use PPE and those that used it sometimes (13.04\%).

The time of work and the otorrhea symptom were also significantly associated, with greater frequency $(8.69 \%)$ among those with less than 3 years of work in comparison with the other scales of working time, since the absence of 
Table 4. Association between risk factors and signs and symptoms reported by the 23 rural workers exposed to pesticides from Piedade de Caratinga, MG.

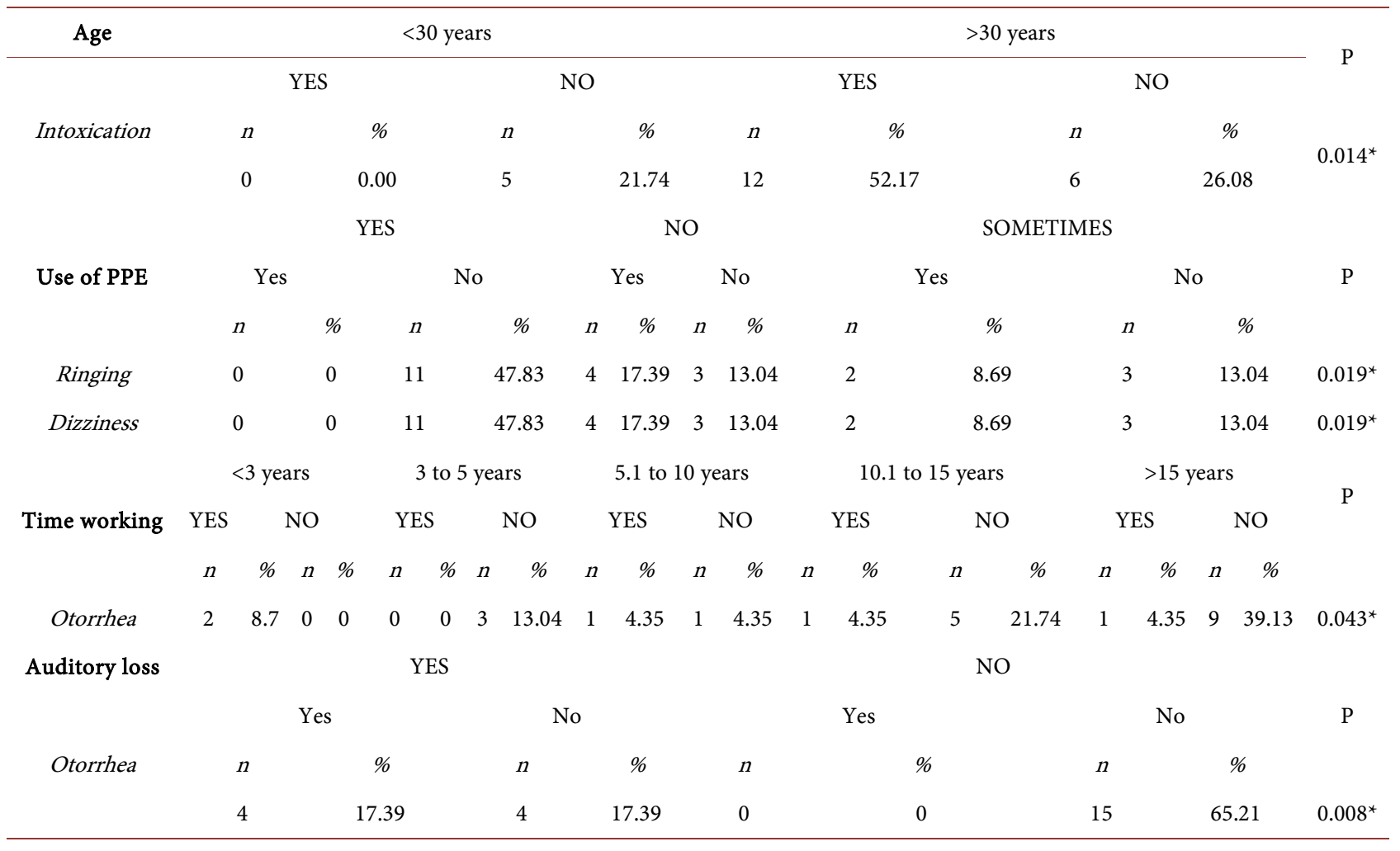

Test of $\chi 2{ }^{*} \mathrm{P}<0.05$.

this complaint was more frequent in individuals with time worked greater than 15 years (39.13\%). Otorrhea is also significantly associated with auditory loss, being more frequent in those diagnosed as having hearing loss (17.3\%), however, the same percentage is observed in other workers who had hearing loss, but who did not report otorrhea (Table 4).

\section{Discussion}

The sample of rural male workers who were evaluated in the present study, were characterized by the mean age of $36.7 \pm 9.3$ years, with a low level of schooling, with a monthly income of minimum wage, with a daily working period of 8 hours and with work time greater than 15 years, being that the majority do not smoke despite the predominance of alcohol among them.

Nunes when analyzing the occupational-environmental and health conditions of vegetable farmers exposed to pesticides in the district of Patrocinio de Caratinga (MG) which stated that they were all males, predominantly from 15 to 21 years of age (37\%), education from 1 to 4 years (47\%), service time from 61 to 120 months (43.33\%) and the salary range up to a current minimum wage (66.67\%). These results suggest that olive growers are younger than the individuals surveyed here, which is possibly related to a shorter service life when compared to the sample in this study; however, the educational level and salary range are similar to our findings [19]. 
Considering also the presence of young people in the application of pesticides in crops, small and medium-sized farmers seem to have knowledge about the risks of pesticides to their health. So, they admit that in a few years of applying the products, it is necessary to hire younger employees for the activity, because they do not feel able to do so any more. According to this author, these young people are "hired" at around 17 and when they turn 25, or 26, they are no longer able to continue in the "service" [20].

Rural workers of Teresópolis were analyzed in a sample of 18 individuals in a study on ototoxicity promoted by pesticides. In the socioeconomic profile, the authors describe the study population as composed of individuals with a mean age of 39.6, similar to the one described here, who worked for more than 21 years and with a workday of 10 hours or more [10].

In the case of tobacco producers from Povoado Colônia Treze, Lagarto County (Sergipe) exposed to pesticides, the mean age was $33 \pm 12.045$ years and a working period of 16 years [21]. This is similar to that found in our results.

The findings regarding the use and management of pesticides along with the use of PPE and the hygiene measures of the interviewees show a disturbing picture. It is observed that the association of Roundup ${ }^{\circledR}$, mainly, or Vertmec ${ }^{\oplus}$, classified as class III, with others characterized as class I such as Manzate ${ }^{\oplus}$, Meotrin $^{\oplus}$ and Tamaron ${ }^{\circledR}$ is common.

The toxicity of most pesticides is expressed in terms of the oral average Lethal Dose (LD50), represented by milligrams of the active ingredient of the product per kilogram of live weight, required to kill $50 \%$ of the rat or other animal population test. The LD50 is used to establish the safety measures to be followed to reduce the risks that the product may present to human health. According to this classification the pesticides belonging to class I are considered extremely toxic. Those in class II are highly toxic, those in class III are moderately toxic and those in class IV are fairly toxic [22].

The rural workers of Piedade de Caratinga expose themselves to the deleterious effects of these products when preparing and applying them with the use of the manual knapsack applicator and most of them prefer not to use or to use only sometimes the PPE. This fact represents a great risk for this population, which is consistent with that described in another study that investigates the risks determined by the inappropriate use and management of pesticides for the rural worker [18].

The effects of prolonged use of pesticides have been well established in numerous national and international studies that describe chronic adverse effects, depression and suicide [23], immunological alterations [24] [25], impairments in reproductive function [26] [27], neurotoxic effects, gastrointestinal effects [28], genotoxic [29], neurotoxic [30], and cancer [31] [32].

Our results suggest a high incidence of auditory loss in the population surveyed with a percentage of $34.8 \%$, considering conductive and sensorineural loss. The relationship between sensorineural auditory loss and ototoxicity promoted by pesticides is already well established by other studies [3] [9] [10] [33] 
and, when considering only rural workers with sensorineural loss, the incidence is $13.04 \%$.

The comparison between the findings found in our study and those found in similar studies may become difficult, since studies of the prevalence of hearing impairments in Brazil are still scarce and, when they are performed, follow different methodologies [34].

In a study of 18 rural workers, aged 16 to 59 years, occupationally and environmentally exposed to organophosphorus pesticides from the city of Teresópolis $(\mathrm{RJ})$, they observed that the incidence of sensorineural hearing loss in this population was $38.9 \%$, above that observed in our findings. This difference may be conditioned by inequalities in the methodology used here, since we do not work with individuals over 50 years of age and do not use the vectoelectronystagmography test [10].

As a way of confirming that the hearing loss presented by the individuals of this study is directly related to the use of organophosphorus pesticides, we opted to exclude those workers who handled heavy machinery, due to the noises, those that presented changes in the meatoscopy, as well as those with age range over 50 years.

Teixeira et al [7] carried out a study of prevalence with 98 workers exposed to organophosphorus and pyrethroids pesticides used in vector control campaigns. The workers were divided into 2 groups. Group 1 reported no exposure to noise in current and past work and/or leisure life, and group 2 reported exposure to noise in current or previous work and/or leisure life. Of those exposed only to insecticides, $63.8 \%$ had hearing loss; for the group with simultaneous exposure to insecticides and noise, hearing loss was $66.7 \%$. The authors concluded that there is evidence that exposure to pesticides induces peripheral auditory damage, and that noise is a factor that interacts with pesticides, optimizing their ototoxic effects.

Similar studies have concluded that chemicals can induce hearing loss, regardless of the presence of noise, but this could act as an intensifier of hearing loss [8] [9] [10].

The results described here suggest that the impression of the auditory health of the rural workers interviewed did not always correspond to what was observed through the diagnostic exams. This fact can be understood by the possible association with the impairment of sound frequencies, since among individuals with sensorineural loss, the fact that there is no compromise in the lower frequencies, which correspond to the sound of speech, could contribute to the sensation of everything being well, since they would not have limitations to communicate.

Among those with conductive loss, the impression that the right ear presented less acuity than the left can also be understood by the audiometry results, since the right ear had a higher percentage of involvement in the frequencies of 250 to $500 \mathrm{~Hz}$ than the left one, which compromises the audition in the speech exercise.

The perception of loss of auditory acuity between those diagnosed with senso- 
rineural loss and conductive loss, where it was observed that the first claim to not have auditory problems, possibly related to bilateral loss among those who had the compromised bone pathway, thus allowing their adaptation. As carriers of conductive losses often have unilateral involvement, this difference in acuity from one ear to the other is better perceived.

Other work also report a study done with individuals exposed to various types of pesticides, among them organophosphates, the presence of sensorineural loss with bilateral impairment and alterations in their auditory thresholds for the highest frequencies from $3 \mathrm{kHZ}$ to $6 \mathrm{kHZ}, 8 \mathrm{kHZ}$, which is consistent with our results [9].

Sensorineural hearing loss is similar to that seen in the loss caused by medication and other drugs or by noise, where a bilateral, symmetrical and irreversible lesion of the hair cells is installed, with changes in hearing thresholds of $3 \mathrm{kHz}$ to $6 \mathrm{KHz}$, which also coheres with our results. [35]

The results that indicate that all individuals sampled in this study present normal meatoscopy can be explained by the presence of alterations in this test was exclusion criterion defined in the methodology for definition of the sample. This criterion was established due to the importance of the meatoscopy in the identification of the functional integrity of the middle ear, considering possible lesions such as obstruction of the external acoustic conduit, perforated tympanic membrane and auditory deficiency of non-occupational origin already diagnosed [7].

The reports of ringing in the ears, dizziness and intoxication become relevant in understanding the first signs indicative of injury promoted by pesticides. Thus, in a study about the self-perception of auditory and vestibular health in rural workers in Teresópolis (RJ) exposed to pesticides, it was stated that in $76 \%$ of the subjects, dizziness was reported at one point in life and $58 \%$ still feeling dizzy, 54\% felt ringing in the ears; $46 \%$ felt congested ears, $74 \%$ thought they had good auditory acuity, but $70 \%$ felt they had difficulties understanding words, suggesting that pesticides can induce alterations of the auditory and vestibular system through a slow and silent intoxication [36].

In a study involving rural workers exposed to pesticides and noise, it was observed that most of the individuals sampled presented as auditory complaints ringing in the ears and dizziness after the working day. These auditory complaints are frequent among those who presented some type of auditory impairment [9].

Among the rural workers exposed to pesticides in Piedade de Caratinga, the slow and silent effect of the pesticide on hearing health was also observed, promoting the presence of signs and symptoms such as ringing in the ears, dizziness and intoxication. They were more frequent, especially in those who declared they did not use PPE and were older than 30 years.

Through this study it can be observed that the auditory and vestibular system of the rural workers exposed to these toxic agents deserve to be evaluated periodically by health teams. In addition to receiving training on the prevention of 
risk factors, appropriate use of PPE and management of these agents that does so much harm to the health as a whole.

The significant association between work period and otorrhea found in our results showed a higher frequency among individuals under the age of 30 years. In the literature, several factors, such as viral and bacterial infections, structural and physiological impairment of the Eustachian tube, cigarette and allergic response are observed as causes of otorrhea [37]. The pesticides were related to allergies that afflict the skin, the respiratory system and other body sites [38]. However, the absence of information regarding the presence of allergic disease in the individuals analyzed in the sample of this study makes it impossible to prove the relationship between higher frequency of allergic response to pesticides among the youngest individuals in the sample and the presence of otorrhea.

The relationship between otorrhea and conductive loss described here is consistent with those developed by different authors such as Silva who investigated the hearing loss ratio in children and adolescents diagnosed with HIV [39]. Hyppolyte [40] also establishes this relationship in review on conductive hearing losses. Our findings are consistent with what these authors claim.

\section{Conclusions}

The results of this study show that most of the 23 rural workers surveyed use organophosphorus pesticides and pyrethroids. They claim to have information about the risks of working with pesticides, but did not receive training on first aid and disposal of PPE. A high prevalence of auditory and vestibular complaints can be observed, being the conductive loss more frequent than the sensorineural one, suggesting that these substances can offer risks to the systems due to their ototoxic and neurotoxic actions.

Since the sample size was defined for convenience, it counted with a limited number of participants, it is suggested that other works should be developed with a larger sample in order to better understand this association between hearing loss and use of organophosphates.

However, it is essential that all health professionals are aware of the risks related to the use of pesticides and auditory health. And they understand their role in the prevention, control and treatment of diseases within essentially agricultural communities, such as those that form the mesoregion of Rio Doce.

\section{Acknowledgements}

To all who contributed directly or indirectly to the conclusion of this work.

\section{References}

[1] ABRASCO-Brazilian Association of Collective Health. Dossier-An Alert on the Impacts of Pesticides on Health [Internet]. Rio de Janeiro, 2012. 135 p.

http://www.abrasco.org.br/dossieagrotoxicos/wp-content/uploads/2013/10/DossieA brasco_2015_web.pdf 
[2] SINITOX-National System of Toxic-Pharmacological Information [Internet]. Center for Scientific and Technological Information, Oswaldo Cruz Foundation. Rio de Janeiro. 2012. http://sinitox.icict.fiocruz.br/

[3] Korbes, D., Silveira, A.F., Hyppolito, M.A. and Munaro, G. (2010) Changes in Vestibular System Due to Exposure to Pesticides: Literature Review. Revista da Sociedade Brasileira de Fonoaudiologia, 15, 146-152.

[4] Teixeira, C.F., Giraldo, S.A. and Morata, T.C. (2002) Occupational Exposure to Insecticides and Their Effects on the Auditorys. Noise Health, 4, 31-39.

[5] Taguchi, C.K., Uchara, I., Ganança, M.M., Caovilla, H.H. and Ito, Y.I. (1990) From the Vestibular Evaluation in 42 Patients with Ototoxicosis. International Scientific Meeting Proceedings Prof. George Postmann, Sao Paulo, 1.

[6] Kos, A.O. and Kos, M.I. (2003) The Etiology of Hearing Loss and Its Audiological Characteristics. In: Fundamentals, F.S., Ed., Speech-Language Pathology and Audiology: Audiology, 2nd Edition, Guanabara Koogan, Rio de Janeiro-RJ, 123-140.

[7] Teixeira, C.F., Augusto, L.G. and Morata, T.C. (2003) Auditory Health of Workers Exposed to Noise and Insecticides. Public Health Journal, 37, 417-423.

[8] Azevedo, A.P. (2004) Effect of Chemicals and Noise on the Genesis of Occupational Hearing Loss [Dissertation]. [Rio de Janeiro]: Oswaldo Cruz Foundation, National School of Public Health, 162 p.

[9] Manjabosco, C.A., Morata, T.C. and Marques, S.J. (2004) Audiometric Profile of Agricultural Workers. International Archives of Otorhinolaryngology, 8, 284-295.

[10] Hoshino, A.C.H., Ferreira, H.P., Taguchi, C.K., Tomita, S. and Miranda, M.F. (2008) Study of Ototoxicity in Workers Exposed to Organophosphates. Revista Brasileira de Otorrinolaringologia, 74, 912-918. https://doi.org/10.1590/S0034-72992008000600015

[11] Brazilian Institute of Geography and Statistics, Department of Statistics Research (DPE) and Social Indicators, Demographic Census (2010) Characteristics of the Population and Households. http://www.ibge.gov.br

[12] Gabriel, G.F. (2010) Environmental Health Strategy to Approach the Use of Pesticides and Environmental Health: A Case Study in São Vicente do Grama District of the City of Jequeri-MG. Dissertation, University Center of Caratinga, Caratinga, 102 p.

[13] Gonçalves, W.A. (2005) Evaluation of the Causes and Effects of Contamination by Pesticides Applied to the Tomato Crop, in Rural Workers of the Municipality of Caratinga-MG. Dissertation, University Center of Caratinga, Caratinga, $82 \mathrm{p}$.

[14] Pinheiro, N.L. (2008) Evaluation of Organophosphate Poisoning of Rural Workers in Tomato Culture. Dissertation, University Center of Caratinga, Caratinga, 115 p.

[15] Rossatto, L.M. (2008) Occurrence of Enteroparasites in Elementary School Students and the Relation with Basic Sanitation in the City of Piedade de Caratinga-MG. Dissertation, University Center of Caratinga, Caratinga, $84 \mathrm{p}$.

[16] Gil, A.C. (1999) Methods and Techniques of Social Research. 6th Edition, Atlas, São Paulo, $220 \mathrm{p}$.

[17] American Speech-Language Hearing Association (1990) Guidelines for Audiometric Symbols. Asha, 32, 25-30.

[18] Kos, M.I.A. (2012) Effects of Exposure to Pesticides on the Efferent Auditory System through Transient Otoacoustic Emissions with Suppression. Thesis, UFRJ, Rio de Janeiro, $132 \mathrm{p}$.

[19] Nunes, M.C.M. (2006) Analysis of the Occupational-Environmental and Health 
Conditions of Pesticides Exposed to Pesticides, in Patrocinio de Caratinga, MG. Dissertation, University Center of Caratinga, Caratinga, $112 \mathrm{p}$.

[20] Gomide, M. (2005) Agrotoxic: What Name to Give? Science \& Collective Health, 10, 1047-1057.

[21] Sena, T.R.R., Vargas, M.M. and Oliveira, C.C. (2013) Auditory Health and Quality of Life in Workers Exposed to Pesticides. Science and Collective Health Magazine, 18, 1753-1761.

[22] EMBRAPA-Brazilian Agricultural Research Corporation (2006) Reference Frame in Agroecology. Brasilia.

https://www.alice.cnptia.embrapa.br/alice/bitstream/doc/107364/4/Marcoreferencia l.pdf

[23] Chrisman, J.R., Koifman, S., de Novaes, S.P., Moreira, J.C., Koifman, R.J. and Meyer, A. (2009) Pesticide Sales and Adult Male Cancer Mortality in Brazil. International Journal of Hygiene and Environmental Health, 212, 310-321.

[24] Chatzi, l., Alegakis, A., Tzanakis, N., Siafakas, N., Kogevinas, M. and Lionis, C. (2007) Association of Allergic Rhinitis with Pesticide Use among Grape Growers in Crete, Greece. Occupational and Environmental Medicine, 64, 417-421.

[25] Okabe, M., Nishimoto, S., Sugahara, T., Akiyama, K. and Kakinuma, Y. (2010) Oral Administration of Paraquat Perturbs Immunoglobulin Productivity in Mouse. The Journal of Toxicological Sciences, 35, 257-263. https://doi.org/10.2131/jts.35.257

[26] Koifman, S., Koifman, R.J. and Meyer, A. (2002) Human Reproductive System Disturbances and Pesticide Exposure in Brazil. CAD Public Health, 18, 435-445.

[27] Gibson, G. and Koifman, S. (2008) Agrochemical Consumption and Temporal Distribution of the Proportion of Male Births in the State of Paraná, Brazil. Panama Public Health, 24, 240-247.

[28] Landrigan, P.J., Sonawane, B., Butler, R.N., Trasande, L., Callan, R. and Droller, D. (2005) Early Environmental Origins of Neurodegenerative Disease in Later Life. Environmental Health Perspectives, 113, 1230-1233. https://doi.org/10.1289/ehp.7571

[29] Bolognesi, C. (2009) Genotoxicity of Pesticides: A Review of Human Biomonitoring Studies. Mutation Research, 543, 251-272.

[30] Tanner, C.N., Ross, G.W., Jewell, S.A., Hauser, R.A., Jankovic, J., Factor, S.A., Bressman, S., Deligtisch, A., Marras, C., Lyons, K.E., Bhudhikanok, G.S., Roucoux, D.F., Meng, C., Abbott, R.D. and Langston, J.W. (2009) Occupation and Risk of Parkinsonism: A Multicenter Case-Control Study. Archives of Neurology, 66, 11061111. https://doi.org/10.1001/archneurol.2009.195

[31] Alavanja, M.C., Sandler, D.P., Lynch, C.F., Knott, C., Lubin, J.H., Tarone, R., Thomas, K., Dosemeci, M., Barker, J., Hoppin, J.A., Blair, A., et al. (2005) Cancer Incidence in the Agricultural Health Study. Scandinavian Journal of Work, Environment \& Health, 31, 39-45.

[32] Turner, M.C., Wigle, D.T. and Krewski, D. (2010) Residential Pesticides and Childhood Leukemia: A Systematic Review and Meta-Analysis. Environmental Health Perspectives, 118, 33-41.

[33] Teixeira, C.F. and Brandão, M.F.A. (1998) Effects of Agrochemicals on the Auditory System of Rural Workers. Caderno Informativo de Prevenção de Acidentes, 19, 218.

[34] Cruz, M.S., Oliveira, L.R., Carandina, L., Lima, M.C.P., César, C.L.G., Barros, M.B.A., Alves, M.C.G.P. and Goldbaum, M. (2009) The Prevalence of Referred Hearing Loss and Attributed Causes: A Population-Based Study. Caderno de Saúde Pública, 25, 1123-1131. 
[35] Morata, T.C. and Little, M.B. (2002) Suggested Guidelines for Studying the Combined Effect of Occupational Exposure to Noise and Chemicals on Hearing. Noise Health, 4, 73-87.

[36] Hoshino, A.C.H., Ferreira, H.P., Tagush, C.K., Tomita, S. and Miranda, M.F. (2009) Self-Perception of Auditory and Vestibular Health of Workers Exposed to Organophosphates. CEFAC Magazine, 11, 681-687.

[37] Brazil, Ministry of Health, Secretariat of Health Care and Department of Basic Attention (2012) Reception to Spontaneous Demand: Most Common Complaints in Primary Care/MS, Department of Health Care, Department of Primary Care. Ministry of Health, 2, 290.

[38] Braibante, M.E.F. and Zappe, J.A. (2012) The Chemistry of Agrochemicals. New Chemistry in School, 34, 10-15.

[39] Silva, A.M. (2011) Evaluation of Hearing Loss in Children and Adolescents with HIV/AIDS. Doctoral Thesis, University of São Paulo, São Paulo.

[40] Hyppolito, M. (2005) Conductive Hearing Loss. Medical Magazine Ribeirão Preto, 38, 245-252.

\section{Scientific Research Publishing}

Submit or recommend next manuscript to SCIRP and we will provide best service for you:

Accepting pre-submission inquiries through Email, Facebook, LinkedIn, Twitter, etc. A wide selection of journals (inclusive of 9 subjects, more than 200 journals)

Providing 24-hour high-quality service

User-friendly online submission system

Fair and swift peer-review system

Efficient typesetting and proofreading procedure

Display of the result of downloads and visits, as well as the number of cited articles

Maximum dissemination of your research work

Submit your manuscript at: http://papersubmission.scirp.org/

Or contact jbm@scirp.org 